\title{
Re: Impact of pelvicalyceal anatomy in treatment with shock wave lithotripsy and flexible ureterorenoscopy of lower pole renal stones
}

\author{
Nevzat Can Sener • Abdurrahim Imamoglu • \\ Okan Bas · Ufuk Ozturk · Goksel Goktug • \\ Can Tuygun · Hasan Bakirtas
}

Received: 1 July 2014 / Accepted: 15 July 2014 / Published online: 12 August 2014

(C) Springer-Verlag Berlin Heidelberg 2014

\section{Dear Editor,}

We thank you for this opportunity to publishing our article as well as this response letter. In the article, we compared patients treated by flexible ureterorenoscopy (F-URS) against shock wave lithotripsy (SWL), in lower pole stones smaller than $1 \mathrm{~cm}$. In the article, we excluded the patients with steep $\left(<30^{\circ}\right)$ infundibulopelvic angles (IPA) [1]. Recently, we were made aware of a letter, proposing including the patients we excluded.

We thank the authors for proposing the article, but we believe it would be best to exclude the patients with steep IPA. In European Association of Urology guidelines on Urolithiasis, it is proposed that worse success rates are accomplished when IPA is $<30^{\circ}$ [2]. Even though SWL is still recommended for lower pole stones, we believe patients with steep infundibulopelvic angles would add considerable bias to the study against SWL.
If the goal is to investigate the lower pole anatomy on success and complication rates especially for SWL, the study design should be constructed differently. As there are abundant samples in the literature, we did not plan to clear the path to treat lower pole stones with complex lower pole anatomy, but we look forward to reading the article by the authors.

Conflict of interest None.

\section{References}

1. Sener NC, Abdurrahim Imamoglu M, Bas O et al (2013) Prospective randomized trial comparing shock wave lithotripsy and flexible ureterorenoscopy for lower pole stones smaller than $1 \mathrm{~cm}$. Urolithiasis. doi:10.1007/s00240-013-0618-z

2. Turk C, Knoll T, Petrik A et al (2013) Guidelines on urolithiasis. European Association of Urology

\footnotetext{
N. C. Sener $(\bowtie)$

Numune Teaching and Research Hospital, Adana, Turkey

e-mail: cansener14@gmail.com

A. Imamoglu · U. Ozturk · G. Goktug · C. Tuygun · H. Bakirtas

Diskapi Teaching and Research Hospital, Ankara, Turkey

O. Bas

Dr. Abdurrahman Yurtarslan Onkoloji Training and Research

Hospital, Ankara, Turkey
} 